\title{
BULGARIAN PLAYGROUNDS IN TRANSITION: DO CHILDREN'S AND PARENTS' PERCEPTIONS DIFFER?
}

\author{
TURKAN FIRINCI ORMAN ${ }^{1}$
}

\begin{abstract}
Focusing on ideological dualism reflected in children's playgrounds in Bulgaria, this paper examines cross-generational differences in parents' and children's perceptions of playgrounds and their equipment designed during the Cold War and post-Cold War periods, respectively. This political conception of playgrounds evokes and aligns with Winner's (1980) theory and work, "Do artifacts have politics?" Both qualitative and quantitative methods were used within a mosaic approach that incorporated a range of techniques for eliciting young children's views about extant playground models. The findings of this descriptive analysis provide evidence that both children and their parents endorsed post-Cold War playground designs in Bulgaria because of their better functionality. However, their perceptions differed on functional playground dimensions such as joy, safety, nature, socialization, and design. Significantly, Cold War playground designs were praised for their notable affordance of children's socialization.
\end{abstract}

KEYWORDS: ideology, children's participation, playground design, mosaic approach, functional playground dimensions

1 Turkan Firinci Orman is assistant professor at the Department of Sociology, Baskent University, Turkey, e-mail: turkanfirinci@gmail.com 


\section{INTRODUCTION ${ }^{2}$}

The collapse of Communism and the shift to a liberal democracy completely transformed Bulgarian society and dramatically affected people's social, political, and economic existence. Moreover, it influenced children's social and physical environments.

Recent studies have reported that following the collapse of Communism, socialist-influenced urban planning in Bulgarian towns has been abandoned (Hirt 2005, Holleran 2014). The resulting loss of children's play environments has been a negative outcome of this shift (Raycheva et al. 2004). A significant proportion of inter-building areas, used by children for playing games, have been converted into shops, apartment blocks, or parking lots because of legislative discrepancies in the rules for restituting real estate to former owners. Moreover, the official Bulgarian State Newspaper published an ordinance in 2009 detailing terms and conditions regarding playground equipment and safety. Under the new guidelines, playground equipment must meet specific EU standards. Existing equipment at the time of the ordinance, mostly reflecting designs of the Cold War period, did not meet the new standards. Consequently, 2014 was set as the deadline for their replacement.

This mandatory collective revamping of playgrounds, initiated by the Bulgarian government, is a massive project that has contributed to the hybrid appearance of many playgrounds. In light of the importance of this moment in Bulgarian history, and focusing on the ideological dualism reflected in playgrounds, the research this paper describes examined cross-generational differences in children's and parents' perceptions of Bulgaria's playgrounds, where children play using old and new equipment designed during the Cold War and post-Cold War periods, respectively. The main question addressed by this study is: Do children's perceptions of old and new playground designs differ from those of their parents?

The changing policy context in Bulgaria raises new questions. First, children are not usually included in decision-making processes within landscape planning which is mostly managed by adults, for adults. This, we argue, is unsustainable both in the short- and long-terms. Apart from typically being a dull environment, the school playground is an adult-controlled setting where restrictions are often shaped by safety concerns. Children are thus relatively powerless in the face of adult control (Meire 2007). However, greater involvement of children in the

\footnotetext{
2 Acknowledgements: I would like to thank Georgi Stankov, a Bulgarian psychologist, and all of the volunteers in Haskovo who made the fieldwork for this study possible. I am especially grateful to my husband and daughter for their patience and support.
} 
design process could allow for more engagement with the actual users of these spaces - those who push the boundaries set by adults - and who themselves experience play activities.

Importantly, Bulgarian playgrounds are in a state of transition, and little is known about the perceptions of children and their parents toward them. During a period of more than 30 years, children's participation in spatial designing has attracted increased attention among policymakers, designers, and researchers in Western countries (Keenan 2007; Roe - Scott 2008). Hasirci (2008), who examined children's perspectives in architecture, showed that eliciting children's views of their own childhood and daily experiences was particularly significant. For example, young children can make insightful comments about their indoor and outdoor spaces. Such information can inform changes to existing facilities or contribute to new building designs. Thus, soliciting children's and parents' perceptions of existing playground designs could facilitate policymakers and designers in incorporating children's needs into equipment design and improve the functionality and sustainability of playgrounds.

Various studies on play have shown that adult-designed spaces do not maximize the potential for children's engagement in active types of physical and mental play (e.g., Cunningham et al. 1996). However, parental influence is one of the major determinants of children's outdoor play behaviors (Valentine 2004). Therefore, much of the research has sought adults' perspectives on the suitability of children's play spaces - particularly focusing on why they would choose to allow, or disallow, their children from playing in them (Herrington 2008).

Several qualitative studies aimed at providing an evidence base for improving children's play areas have been conducted. These applied ethnographic methods (Gharahbeiglu 2007) and in-depth interviews focusing on users' needs for gathering data from children, parents, and teachers (Percy-Smith 2002, Herrington 2008). Application of quantitative techniques has also revealed that colorful playground settings can increase children's physical activity levels (Herrington 2008).

Research findings further suggest that nature constitutes an important dimension in children's play spaces. Groves and McNish (2008), for example, have found that children frequently mention natural features as part of their discourse on play spaces. By contrast, despite children's enjoyment of being in nature, and its positive effects on their physical well-being and creative play (Frost 2006, Parsons 2011), nature is often a missing component in adultdesigned playgrounds.

There is also a significant body of research on playground safety, focusing, understandably, on the need to decrease the risk of injury. However, scholars' 
attitudes toward safety reflect ambivalence. Sandseter and Kennair (2011), for example, opposed a safety focus, claiming that children's risky play behavior in the playground, which mirrors effective cognitive behavioral therapy for addressing anxiety, could positively influence their development.

Developmental psychologists often focus on children's socialization associated with playgrounds (Butcher 1993, Soler-Adillon et al. 2009, Solomon 2014). That is, opportunities to interact, communicate, exercise, and improve their social skills in the playground enable children to connect with their peers. In a constructivist model, children are considered active agents and eager learners constructing their social world (Corsaro 2011:9). Furthermore, hanging out, talking with each other, or playing sedentary games constitute $19 \%$ to $30 \%$ of activities in places within the habitual range of children (Korpela 2002), highlighting the importance of social interaction for children.

Studies have shown that playgrounds have the greatest impact on child development. They suggest that playground design affects children's social and physical development (Barbour 1999, Ginsburg 2007). A well designed playground should stimulate four aspects of a child's development: physical, emotional, social, and cognitive.

While both qualitative and quantitative studies of playgrounds have attended to the motives of children and/or their parents, individual studies have tended to focus on just one aspect of playground functions. Rather than focusing on a particular functional dimension, this study adopted an integrated approach encompassing five dimensions: joy, safety, design, nature, and socialization. These five components, which were the study's main variables, were conceptualized as functional playground dimensions (FPDs).

The finding of Gantcheva and Kolev (2001) that programs initiated by international organizations have provided extensive support for Bulgarian children in tackling the problems they faced after the collapse of Communism has stimulated a number of studies. However, most of these studies have focused predominantly on specific groups of children, and have not addressed their overall environment.

This paper first provides a brief historical background of Bulgarian playgrounds built in both the old and new styles, and discusses their ideological character in light of Winner's (1980) argument about the relation between politics and artifacts. The next section introduces a mixed methods research design aimed at comparing the perceptions of Bulgarian children regarding existing playground designs with those of their parents relating to their own kindergartens and/or neighborhoods. Crossgenerational differences between parents and children are explored in the data analysis and findings addressing the study sub-questions in the following section. Last, the paper offers conclusions and recommendations for future research. 


\section{HISTORICAL AND POLITICAL CONTEXTS}

The first playgrounds, comprising separate sand areas developed for very young children, are thought to have originated in Germany (Frost 1985). Playground rhymes also evidence a firm historical grounding, and while some of these have hardly changed over successive generations, others have adapted easily to a changing world (Meire 2007). In general, playgrounds have changed substantially over several decades, mainly for safety reasons (Pursell 2011). Specifically, the height of playground equipment has been reduced, and asphalt or concrete plates have replaced cinder/clay surfaces. The stress on playground safety has led to continued design improvements that are reflected in various trends, especially in the Americas.

In his extensive historical evaluation of American playgrounds, Pursell (2011) revealed a dense underlying tangle of technology, politics, economics, class bias, professional aspirations, and cultural idealism behind their construction and design over the past century. He viewed technology as both a cultural process and a cultural product. From the beginning of the last century until the 1920s, children's play was driven by ideologies of science and technology. However, by the mid-century, a shifting trend reflected the presence of new media and child consumerism. Disneyland can be viewed as a concrete outcome of this trend. Thus, playgrounds of the post-Cold War era, regardless of whether they belong to classical schoolyards, European adventure parks, play areas at McDonalds, or reflect other contemporary designs, present a conglomeration of philosophy and/or ideology, design, and equipment.

Over the last century, some types of playground equipment in Communist countries, notably in the Soviet states and Eastern Europe, have been marked by Cold War ideological passions and trends. These include: climbing frames shaped like rockets and earth-like spherical structures, together with swings, slides, and carousels. Following the traditions of Cold War societies, this equipment was designed and produced by state-owned factories. Emulation of the Soviet playground model was apparent in the details of Bulgarian playground equipment and contributed to the creation of special cultural perceptions of outdoor play. In 1979, the first Bulgarian astronaut, Georgi Ivanov became a hero within social narratives. During this period, many children dreamed of becoming astronauts. Thus, the rocket design of the old Bulgarian playgrounds can be interpreted as a direct representation of Cold War ideology.

Not only rockets and earth-resembling climbing frames, but also double-seated swings, usually in back-to-back positions, characteristically reflected the social and moral codes of Bulgarian society, namely that every child was expected to share their seat with another child while swinging. Following Bulgaria's social 
transformation toward a liberal democracy, renovated playgrounds representing the post-Cold war spirit in relation to children's spaces evidently portray a far more individualistic approach than the old equipment (Firinci - Stankov 2013: 3-4). Thus, the conceptual opposition between playgrounds of the Cold War and post-Cold War periods is based on their respective historical backgrounds and designs. Existing Bulgarian playgrounds of the Cold War period, reflecting a collectivist style, were constructed during the late 1960s, whereas renovated post-Cold War playgrounds reflect an individualistic and contemporary design.

The collectivist versus individualistic conceptual opposition is grounded in social and cultural inquiry and refers to a variety of phenomena such as social systems, morality, religion, cognitive differentiations, economic development, modernity, social pathology, and psychological well-being (Hofstede 1991, 2001). The conceptualization of collectivism pertains to societies in which from their birth onward individuals are integrated into strong, cohesive ingroups, which continue to protect them throughout their lifetimes in exchange for unquestioning loyalty. By contrast, individualism is conceived in relation to societies in which ties between individuals are loose, with the expectation that each individual will look after himself or herself and his or her immediate family. Within this definitional scope, Solomon (2014:28) claims that playgrounds reflect societal values and attitudes. In Scandinavia, for example, the collectivist ethos entails individuals supporting and aiding each other, whereas in the individualist mode, each individual only watches out for himself or herself. Shaped within a collectivist mold, Nordic societies emphasize life skills and socialization in playgrounds. By contrast, in the English-speaking world, and especially in the United States and Australia, an individualistic focus and an early education prototype that values content and testing over socialization or communal understanding prevail (Solomon 2014:29). Thus, collectivist cultures stress communal needs, shared goals, and cooperation, while individualistic cultures focus on individuals' desires and benefits (Cox et al. 1991).

Along with playgrounds' historical backgrounds, their political faces also merit attention. This raises the question of what really shapes the distinction between playground designs of the Cold War and post-Cold War periods. However, any conceptualization of the political qualities of playgrounds should avoid extreme technical determinism, social constructivism, and noetic flatness. In his essay, "Do artifacts have politics?" Winner (1980) presented a comprehensive analysis, identifying the ways in which artifacts can demonstrate politics. According to Winner (1980:123), there are "two ways in which artifacts can contain political properties. First are instances in which the intervention, design, or arrangement of a specific technical device or system become a way of setting an issue in a particular community." Winner considered such examples to often be obvious, 
easily identifiable, and understandable. "In the design version, someone wills a specific social state, and then suitably transfers this intention into the artefact" (Jeorges 1999:412). Winner (1980:123) described the second type of artifact as "inherently political technologies, man-made systems that appear to require, or to be strongly compatible with, particular kinds of political relationships."

Considering the importance of design and its reflection of a specific society - Winner's first type of politically infused artifacts - we can argue that Cold War playground designs promoted collectivist behavior among children while conveying the same message to the wider community. By contrast, post-Cold War playground designs could be interpreted as promoting individualistic behavior in children and, thereby, child consumerism (by supporting the ideas of a consumer society). Thus, ideology, as a symbolic power, is visible in the different styles of Cold War and post-Cold War playground designs, offering important insights.

\section{METHODS}

\section{Study Questions}

This study was designed to compare perceptions of young children and their parents regarding Cold War and post-Cold War playground designs in the context of dramatic processes of societal change within Bulgaria. A special model combining quantitative and qualitative methods was developed to answer the following questions:

1. Is there a significant difference between children's and parents' perceptions of FPDs?

2. Do playground equipment designs (of the Cold War or post-Cold War periods) affect children's and parents' prioritization of FPDs?

3. Of the two kinds of playground designs (those of the Cold War and postCold War periods, respectively), which is more responsive to children's and their parents' needs/expectations?

Because study participants included both children and adults, it was necessary to combine qualitative and quantitative techniques for gathering data from both groups. Children's perceptions of extant playgrounds in Bulgaria, and those of their parents, were evaluated based on the prioritization of FPDs. Qualitative 
methods were used to elicit children's views, and the findings were then quantified by applying special tools. In this way, data gathered from parents using quantitative techniques were calibrated with data collected from the children, enabling a comparison of their respective perceptions.

Studies applying diverse methods have revealed that young children are reliable informants and provide valuable and useful information (Clark - Moss 2001, 2011; Einarsdottir 2005, 2007). Studies focusing on children's views of their playgrounds are remarkable for their unique qualitative mosaic methodologies that offer ways of listening to young children (Waller 2006; Jansson 2008).

\section{Mosaic Approach}

The mosaic approach, adopted for this study, is an integrated research approach that combines visual and verbal components (Clark - Moss 2011:1). It thus entails a child-centered and nontraditional methodology (Corsaro 2011:58). Starting from the viewpoint that young children are competent meaning-makers and explorers of their environments, the mosaic approach brings together a range of methods for listening to young children talk about their lives (Clark 2005). This study emphasized children's participation, especially in relation to their perceptions of their own play environments.

\section{Sampling}

The study sample was derived from two pre-selected pilot kindergartens with playgrounds designed during the Cold War and post-Cold War periods, respectively - in Bulgaria's Khaskovo District. Given that the playground tradition is a common feature of in all of Bulgaria's cities, Khaskovo District was assumed to represent the wider population. Based on visits to various kindergartens in Khaskovo, the schools were selected according to the criteria that playgrounds were places where children played under the supervision of their teachers during certain hours. Moreover, playground equipment design should almost completely reflect the old designs characteristic of the Cold War period or the new, renovated designs of the post-Cold War era. It should be noted that such playgrounds typically entail open access and function as public playgrounds for children in their neighborhoods after kindergarten hours. 
This study primarily focused on two sets of data obtained from two different sources - children and parents. Sources were divided into two groups, based on the type of playground equipment on which children usually played: Group 1 comprised those using playgrounds reflecting a post-Cold War playground design and Group 2 comprised those using playgrounds reflecting a Cold War playground design. Thus, pilot kindergartens were selected to collect data from children, and various other public playgrounds in Khaskovo were selected to collect data from parents. The selection criteria for both schools and public playgrounds were intended to identify equipment that was exclusively of the Cold War or post-Cold War periods, respectively.

Forty parents (mostly women aged 35-50 years from heterogeneous socioeconomic classes) and 40 children (aged 6-7 years from heterogeneous socioeconomic classes, of whom $65 \%$ were female) actively participated in the research activities and prioritized the FPDs of public playgrounds in Khaskovo. As a complementary resource within the mosaic research design, 16 female teachers from the pilot kindergartens, aged 35-50 years and with 10+ years of professional experience, also participated in the study.

\section{Data Collection}

In compliance with the mosaic approach, several participatory activities were conducted with children in the pilot kindergartens to collect data. These activities, which included clay modeling by children to sculpt their favorite playground equipment, drawing pictures to illustrate their kindergarten's playground, being interviewed about their own play experiences, and planting flowers in groups in their kindergarten's yard where the playground was located, focused on children's lived experiences (see Table 1).

The activities provided opportunities to collect qualitative data on children's perceptions of their own playgrounds. Moreover, the outputs of the activities, for example, drawings, sculptures, declarations, and insights were used as data sources. Additionally, activities with the theme of a child's "dream playground" were conducted. Interviews and teachers' comments drew on these activities to better understand children's needs and expectations of their current playgrounds.

A special tool was also developed that enabled the transformation of qualitative data into data that were more quantitative in character. Thus, systematic observations from the activities, as well as data from personal interviews held with children, were noted in semi-structured documents maintained for every child. Details of children's preferences were also noted on evaluation documents 
in the context of each FPD. These included their most frequently mentioned (favorite) equipment, and the most visible or conspicuous equipment identified by their activity outputs (e.g., drawings and clay works). If a child's narrative about their favorite equipment (e.g., swings) was mostly in the context of enjoyment, then a joy dimension was favored. If the words were about the colors and shapes of the equipment, then a design dimension was favored. Thus, the data were categorized in these documents before implementing the final phase of the analysis. Last, based upon these contextualized frequencies, FPDs were ordered (prioritized) within each child's information document. In this way, the qualitative data obtained from the children were standardized with the data collected from parents' questionnaires and converted into a numerical format.

The study also explored parents' perspectives on playground equipment of the Cold War and post-Cold War periods in Bulgaria. A special questionnaire was administered to parents based on five FPDs, and development was ranked as an additional dimension to obtain further information about the parents' views on existing playgrounds and about their children's overall development. The questionnaire consisted of 24 positive statements on playgrounds, which parents were asked to rate on a Likert scale. Each parent was then asked to prioritize the FPDs. After conducting a peer-review process, the questionnaire was pilot tested on a few parents/adults to ensure language clarity. A similar (or parallel) questionnaire was prepared for teachers with the same purpose as part of the mosaic methodology.

Observations are an appropriate and important entry point for listening to children, whatever their age. As Clark and Statham (2005) have noted, they are of particular value for gaining a better understanding of younger or less articulate children. Additional data collection tools used for the research activities included notes on declarations, systematic observations on trends, questionnaires, and standardized documents (see Table 1).

To identify general trends within the children's groups, personal interviews were conducted in which children were asked about their dream playgrounds, highlighting the FPDs. Interviews can provide a space for formal conversations with children about their opinions, thoughts, and wishes. In this study, the questions posed to children focused on their personal preferences, and opportunities were available for them to add any other information about their dreams that could then be used for in-depth analyses. The interviews about "my dream playground" were semi-structured to explore children's preferences about the look and content of the ideal playground in which they would like to play. Entailing a set of basic questions, they allowed for flexibility and adjustment according to each child's specific character and situation. Fourteen children - seven from each group - were interviewed as a part of this activity. The interviews were structured as follows; 1) Introduction: start a casual 
conversation, depending on the specific situation; 2) Direct conversation to the topic: connect to previous mosaic-related activities, or mention a specific observation relating to the child during those activities; 3) Main part: ask openended what, how, in what way, and more rarely, why questions.

\section{Data Analysis}

Data analysis entailed horizontal and vertical comparisons made between the two sets of evidence. That is, comparisons were made between Groups 1 and 2 , or between children's and parents' perceptions. Two datasets were collected revealing children's and parents' perspectives. The name "mosaic" refers to the bringing together of different pieces of information from various sources to create a holistic picture of children's views. The accumulated data were then ordered numerically in terms of children's FPD prioritization within each group. To calculate this prioritization, a score ranging from 5 (highest priority) to 1 (lowest priority) for every playground dimension was applied; the total score represented the children's priorities.

Parents' perceptions were calculated as total scores derived from the questionnaires. Each questionnaire item was ranked from 5 (highest) to 1 (lowest), and the total scores from both groups were calculated, compared, and evaluated according to their highest and lowest levels. Moreover, parents' prioritization of FPDs was also graded from 5 (highest priority) to 1 (lowest priority) for every dimension, with the total scores representing the parents' priorities.

\section{Ethics}

Ethical considerations delimited this study, as researchers had to support the best interests of each child. For example, activities such as flower-planting and drawing pictures were restricted by a child's curriculum and also had to be sensitive to the child's interests. Both the research timeframe and data collection were planned to accommodate these considerations.

Strict ethical principles are especially important when working with children because of power differences between participants and investigators (Meg 2005). An ethical approach was adopted during the study's implementation, with only children who were willing to be interviewed being asked to take part in the activity. 


\section{RESULTS}

Question 1: Is there a significant difference between children's and parents' perceptions of FPDs?

There was a significant difference between parents' and children's perspectives in terms of FPD prioritization. In both types of playgrounds, the highest total score for the parents reflected their emphasis on safety as a basic dimension, whereas children appeared to seek joy. In almost all cases, the term "joy" (e.g., expressed as "I love to...") related to play (see Table 2).

Question 2: Does playground equipment design - of the Cold War or postCold War periods - affect children's and parents' prioritization of FPDs?

The type of playground - of the Cold War or post-Cold War period - did affect children's FPD prioritization. The children's interview data were summarized after conducting the picture-drawing, clay-modeling, and flower-planting exercises, play observation, teachers' questionnaires, and the "my dream playground" interviews. The data were quantified from the children's individual documents, in which the frequencies of their narrations were evaluated together with visual outputs of their activities. These qualitative data were arranged in numerical order and FPDs in each child's information document were prioritized. Both groups prioritized joy, but the following dimensions were ranked differently. Two sets of dimensions that changed places in the groups' priority hierarchy were socialization-design and nature-safety (see Table 2).

Socialization was relatively important for both groups, and children showed a strong sense of togetherness:

"I like to sit on the bench with Ismail and talk with him." (6-year-old boy in Group 2)

With some boys, we play at the tires with sand. With others, it is more entertaining. Alone it is really boring." (6-year-old boy in Group 1)

The new playgrounds seem to afford fewer opportunities for children to communicate and interact with each other. Single-seat swings are an example of an individualistic design that decreases social interaction and sharing between children. This could help to explain why children who frequented playgrounds of the post-Cold War era expressed a stronger need for socialization while playing.

By contrast, children who frequented playgrounds designed during the Cold War period appeared to have a stronger need for well-designed and colorful equipment, because the current equipment was old and badly maintained. One child, comparing two different types of equipment, explicitly stated: 
"The plastic slide here is more beautiful than the iron slide in our neighborhood as it has colors. The one in the park does not have [colors]." (7-year-old boy in Group 1)

Moreover, children in Group 2 directly stated what should be changed:

"Let's replace them all [the old equipment] with safe, newer, and nicer [equipment]!" (6-year-old boy in Group 2)

"I want the whole playground with all colors!" (6-year-old girl in Group 2)

These opinions reveal why design was the second most preferred dimension after joy within Group 2. The design and socialization dimensions of the equipment are closely linked because designers can improve both the style and the communication potential of the equipment for the children. One child connected these dimensions as follows:

"I like most the swing with two seats because I can play with other children, not alone." (7-year-old girl in Group 1)

While nature was represented in both types of playgrounds, more recently, the maintenance of natural elements in many of Khaskovo's playgrounds with old equipment has been neglected.

"I want a lot of flowers." (6-year-old girl in Group 2)

Interestingly, children in Group 2 (associated with playgrounds designed during the Cold War period) prioritized safety over nature. This choice was probably associated with memories of getting hurt while playing on old playground equipment. However, this problem should importantly be considered one of unsatisfactory playground maintenance rather than a design problem. Therefore, safety was valued more by children using old (Cold War) playgrounds, because their designs were considered more dangerous than those of playgrounds of the post-Cold War era.

Both children and parents accorded low priority to nature's inclusion, indicating a generally low valuation of this dimension within society. This finding could be attributed to the longstanding Bulgarian design tradition according to which nature within playgrounds is accorded secondary importance as a background to rather than as a primary element of children's spaces. Very few items of playground equipment are made entirely of natural materials. Moreover, the 
landscape is not seen as a play-scape, and the opportunities that nature offers for play are not fully exploited. Generally, children love to be surrounded by trees and flowers. However, when asked to compare artificial playground equipment with natural elements, they tended to prefer the former to the latter.

"These trees and flowers are enough." (7-year-old girl in Group 1) "There should be fewer trees and bushes. In the bushes' place, they should put more swings." (6-year-old boy in Group 2)

The following statement illustrates the positive relation between the design of playgrounds of the post-Cold War era and an increased level of safety:

"I prefer the equipment to be made of plastic, because then we can't hit our heads and feel pain." (6-year-old boy in Group 2)

The type of playground also influenced parents' FPD prioritization in Groups 1 and 2. As expected, the most dramatic difference in FPD prioritization centered on the design dimension (see Table 2). Adults who brought their children to playgrounds with equipment designed during the post-Cold War era regarded design as the least significant dimension of playground functionality. This low prioritization could be related to the condition of the new and brightly colored equipment, which appeals to their children. However, for parents in Group 2, who brought their children to playgrounds with old, neglected, and damaged equipment from the Cold War period, design appeared to be a considerably more important dimension.

An important consideration is that parents' safety-related concerns may be rooted in Bulgarian cultural traditions. Safety encompasses adults' fears, their caretaking conventions and judgments about the degree of their children's maturity and competence, and gendered expectations.

Question 3: Which playground design (from the Cold War or post-Cold War period) is more responsive to children's and their parents' needs/expectations?

The findings showed that playground designs from the post-Cold War era met parents' expectations and needs to a greater extent than those designed during the Cold War period. The parents' questionnaire included an additional dimension, development, to assess their concern regarding overall child development. This playground dimension was not measured among the children as 5- to 7-year-olds are clearly not able to evaluate their own development. A comparison of total FPD scores derived from the questionnaires revealed that parents valued postCold War playground designs more than those of the Cold War period. On a scale 
of up to 2,400 points, the total FPD score for post-Cold War playground designs was 2,120 points, while the total FPD score for Cold War playground designs was just 1,386 points. Further, for parents utilizing playgrounds designed during the post-Cold War era, the total score for the joy dimension (363 points) was the highest while that for the nature dimension (324 points) was the lowest. For parents who frequented playgrounds designed during the Cold War period, the total score for the socialization dimension (298 points) was the highest and that for the safety dimension (177 points) was the lowest. These total FPD scores, indicating parents' perceptions, clearly revealed that renovated post-Cold War playground designs in Bulgaria were better suited to their needs.

The findings for children, based on behavioral observations, teachers' questionnaires and extracts from "my dream playground" interviews, were similar. Playground designs of the post-Cold War era better met children's expectations and needs than those of the Cold War period. Total FPD scores derived from the teachers' questionnaires revealed that teachers at kindergartens with playground equipment designed during the post-Cold War era ranked all dimensions higher (the total score for all FPDs was 367) than those at kindergartens with equipment designed during the Cold War period (the total score of all FPDs was 241).

Observations, considered as an alternative indicator, supported these results. Between November 2012 and June 2013, observations were conducted in 20 public playgrounds in Khaskovo. These revealed that increasing numbers of children and parents were visiting renovated public playgrounds. This trend suggests that playgrounds and equipment reflecting post-Cold War designs are perceived as being more attractive in terms of enjoyment and design, and as safer in terms of materials and facilities than older ones.

Teachers' questionnaires administered for two pilot kindergartens were used as alternative tools to compare teachers' perceptions regarding opportunities that their playgrounds provided children in relation to the five functional dimensions. Similar to the parents' questionnaire, the teachers' instrument included the development dimension. Based on their prioritization of FPDs, teachers' perceptions of post-Cold War equipment design were that it enhanced joy, safety, and nature involvement, but could not ensure complete socialization. By contrast, Cold War playground equipment designs were perceived by teachers as being more thoughtful and functional for achieving socialization, creativeness, and learning.

Thematic interviews on "my dream playground" enabled direct elicitation of children's opinions. The interviews included the following question: "Which are your three favorite playgrounds in your neighborhood?" The respondents' answers predominantly supported the identified trend that children preferred neighborhood 
playgrounds designed during the post-Cold War era. Of the 14 children interviewed, 12 identified playgrounds with new/renovated equipment as being their favorites. The playground at McDonalds featured among these. Additional findings that supplemented the mosaic design enabled the initial qualitative data to be transformed into measurable quantities by integrating them into semi-structured forms documenting observations of children at play (see Table 1).

Children's rankings of their favorite kindergarten playground equipment provided a better understanding of their perceptions. Two activities were associated with the phase, "my most favorite playground equipment": a modeling clay activity and interviews conducted with children. For the first activity, children were invited to sculpt their favorite playground equipment out of clay. For the second activity, children were interviewed about their personal preferences regarding playground equipment. The results obtained from these activities showed that based on frequency of mention, the swing was the children's most favored kindergarten playground equipment, regardless of Cold War or postCold War designs. Almost 50\% of children from Group 1 stated that the swing was their favorite playground equipment. Significantly, four children identified "swings with two seats" as particular favorites. Subsequent interviews revealed that the swing is associated with communication and interaction. For example, it was common to hear phrases such as "I like to be on the swing with friends". Evidently, 6- and 7-year-old children desired to share and be together as part of a group. In other words, the swing was favored because it was perceived as an appealing artifact as well as a mechanism for nurturing children's collectivist spirit. Both groups also stated that they loved items that were absent in their playgrounds. Children in Group 1 specified water pools, live animals, hammock climbing walls, and trains, among other items. Children in Group 2 mentioned rockets found in public neighborhood playgrounds designed during the Cold War period but absent in their yards. The latter revealed that their yard used to have a rocket up to a year ago, but this had been removed because it was broken and shaking. Many of the children mentioned that they missed the rocket. One year later, which is a long period for 6- and 7-year-olds, two children recalled the rocket as their favorite piece of equipment.

It should be noted that the activity centering on "my dream playground" may have been influenced by the context in which it was experienced. That is, the findings suggest that the environment and/or order of activity implementation may have significantly influenced children's perceptions. For instance, "my dream playground" interviews on the children's favorite equipment were conducted with children in Group 1 immediately after the modeling clay activity. During these interviews, they, therefore, talked about a wide variety of play facilities. 
By contrast, for children in Group 2, the "my dream playground" interviews were conducted immediately after the flower-planting activity, generally increasing their sensitivity to the appearance of flowers and plants in their playground area. Without exception, when interviewed, all seven respondents in this Group mentioned flowers. By comparison, four of the seven children in Group 1 viewed flowers as a necessary element of their dream playgrounds.

\section{DISCUSSION}

A range of methods were brought together within a mosaic approach to listen to young children's opinions, and those of their parents, on existing playground models. Three research questions were addressed using data derived from children's and parents' views on playground designs of the Cold War and postCold War periods in Bulgaria.

In general, cross-generational differences in perceptions of FPDs were strongly aligned with traditional Bulgarian societal values as children prioritized joy, while their parents prioritized safety. However, parents who brought their children to play in neighborhood playgrounds reflecting Cold War designs stressed safety issues over other FPDs, as they had witnessed injuries resulting from poor maintenance and inappropriate equipment materials. This conclusion confirms the findings of other studies on parents' playground safety perceptions, namely that children's play spaces must ensure a decreased risk of injuries.

Overall, this study found that both Bulgarian children and their parents prefer playground designs of the post-Cold War era. However, children's perceptions and preferences regarding playground equipment were mainly influenced by its attractiveness, while those of their parents were primarily influenced by the safety dimension. These findings support studies showing how colorful playgrounds attract children, therefore helping to increase children's physical activity levels.

Playgrounds of the Cold War period appear to better promote socialization, as the design itself stresses togetherness and sharing (e.g., the swings are always double-seated). Significantly, Winner's (1980) theory of the politics of artifacts is perfectly aligned with the playground situation in Bulgaria, with ideological elements of the equipment design being clearly visible. Furthermore, the findings of this study suggest that the messages conveyed to children by playground designs - through both implicit and tacit symbols - and the arrangement of the facilities that affect their play practices, directly influence their socialization. It can be argued, then, that children and parents who spend time in playgrounds 
designed during the Cold War period are being enculturated by their physical environment, which helps to promote collectivism (and ultimately, a collectivist culture). Thus, we can understand how playground design and socialization practices have the power to define how children should act in their play practices. This study has also revealed that children's imaginations are limited to what they have previously experienced in their neighborhood playgrounds. Hence, their perceptions are shaped by stimuli received from their physical play environments.

By contrast, playground equipment designs of the post-Cold War era better meet the aesthetic expectations of children and their parents. One plausible explanation for this could simply be that Bulgarian playground equipment from the Cold War period is very old and badly maintained, and is, therefore, less attractive than the colorful, newer equipment. It is important to remember, too, that Bulgarian society is facing physical and social changes, and that the promotion of liberal democracy is transforming the overall mentality. It is interesting, then, that the design heritage of the Cold War period, including that of playgrounds, still endures in Bulgaria, continuing to have a significant impact on children's behavior. Despite this influential legacy, many parents who grew up using these same playgrounds now prefer to bring their children to playgrounds designed during the post-Cold War era. The new ordinance on playgrounds, and the general process of social transformation and environmental renewal in Bulgaria, is predicted to affect not just children but the entire society in the near future.

Another conclusion from this study is that the low priority given to nature by both children and parents indicates a generally low level of societal awareness of the importance of this dimension. Nature was seen as a background as opposed to a primary playground element. However, when children spoke about their play spaces during interviews, they tended to emphasize natural features. In spite of children's enjoyment of being in nature, adult-designed playgrounds often omit this element.

Interestingly, children in both groups tended to like playgrounds that were aligned with their previous play practices, and their descriptions of a "dream" play-scape were mostly limited to what they had been previously exposed to in their neighborhood playgrounds. This suggests that children's imaginations are manipulated by their play environments.

It is important to stress that the study had various limitations stemming from exogenous factors such as traditional childcare practices and the educational culture. Recent studies suggest that teaching young children is mainly viewed as women's work, and the number of male teachers involved in early childhood education is very low, worldwide (Cameron 1997; Cihanoglu 2012). In this 
study, the kindergarten teachers and the primary caregivers (e.g., mothers, grandmothers, or aunts) during after-school hours were all female. Male caregivers (e.g., fathers or grandfathers) were rare. Therefore, achieving a balanced sample of male and female sources was not possible. However, sex representation during interviews (children and parents) was more balanced.

One other relevant exogenous factor was the ongoing transformation process itself, which has affected Khaskovo District. Many kindergarten playgrounds were observed to be hybrid in character. Thus, it was difficult to find a playground with equipment reflecting exclusively Cold War designs. This consequently limited the number of participants (children and parents) in the study.

As previously discussed, children's participation in design processes has recently attracted increased interest. The findings of this study reveal that eliciting both children's and parents' perceptions on playgrounds could be useful for local Bulgarian authorities in deciding on future playground designs. The following recommendations derived from this research are intended for researchers, policymakers, and designers.

It is important that future studies on this topic are gender-sensitive, as it is rare to find fathers/grandfathers supervising their children/grandchildren in playgrounds. Additionally, there are fewer male than female kindergarten teachers.

Limited information resources are available on playground designs. Consequently, more post-Cold War studies on playgrounds, adapting ethnographic and historical methods, should be conducted.

An important finding of this study was the widely held opinion of children that swings are the best playground equipment. Swings could therefore receive priority in future designs.

Given that neither children nor their parents prioritized the nature dimension in their perceptions of playgrounds, the integration of nature into playground design should arguably be more seriously considered.

Last, because the scope of children's imaginations is quite restricted within traditional and modern types of playgrounds, equipment design should provide considerably more space for enhancing children's creativity and sense of adventure.

\section{REFERENCES}

Barbour, Ann C. (1999), "The impact of playground design on the play behaviors of children with differing levels of physical competence", Early Childhood 
Research Quarterly Vol. 14, No 1, pp. 75-98. http://dx.doi.org/10.1016/S08852006(99)80007-6

Butcher, Janice (1993), "Socialization of children's playground skill”, Perceptual and Motor Skills Vol. 77, No 3, pp. 731-738. http://dx.doi.org/10.2466/ pms.1993.77.3.731

Cameron, Claire (2006), "A review of staffing in childcare centers in six countries", Early Child Development and Care Vol. 137, No 1, pp. 47-67. http://dx.doi.org/10.1080/0300443971370104

Cihanoglu, Mine (2012), "Male teachers in early childhood education," in: Aarssen, J and Van Oudenhoven, N, eds., New Horizons: A Fresh Look at Early Childhood Development in Turkey, Ankara, ECD Epistemic Community, pp. 79-84.

Clark, Alison (2005), "Ways of seeing: using the mosaic approach to listen to young children's perspectives," in: Clark, Alison - Kjørholt, Anne Trine - Moss, Peter, eds., Beyond Listening: Children's Perspectives on Early Childhood Services, Bristol, Policy Press, pp. 29-49.

Clark, Alison - Peter Moss (2001), "Ethics in early childhood research," in: MacNaughton, Glenda - Rolfe, Sharne A. - Siraj-Blatchford, Iram, eds., Doing Early Childhood Research: International Perspectives on Theory and Practice, Buckingham, Open University Press, pp. 19-33.

Clark, Alison - Peter Moss (2011), Listening to Young Children: The Mosaic Approach, 2nd ed., London, NCB

Clark, Alison - June Statham (2005), "Listening to young children: experts in their own lives", Adoption and Fostering Vol. 29, No 1, pp. 45-56. http:// dx.doi.org/10.1177/030857590502900106

Corsaro, William A. (2011), The Sociology of Childhood, 3rd ed., Thousand Oaks, Pine Forge Press

Cox, Taylor - Sharon A. Lobel - Poppy L. McLeod (1991), "Effects of ethnic group cultural differences on cooperative and competitive behavior on a group task", Academy of Management Journal Vol. 4, No 34, pp. 827-847. http://dx.doi.org/10.2307/256391

Cunningham, C. John - Margaret Jones - Monica Barlow (1996), Town Planning and Children: A Case Study of Lismore, New South Wales, Australia, Armidale, University of New England

Einarsdottir, Johanna (2005), "We can decide what to play! Children's perception of quality in an Icelandic playschool", Early Education \& Development Vol. 16, No 4, pp. 469-488. http://dx.doi.org/10.1207/s15566935eed1604_7

Einarsdottir, Johanna (2007), "Research with children: methodological and ethical challenges", European Early Childhood Education Research Journal Vol. 15, No 2, pp. 197-211. 
Firinci, Turkan - Georgi Stankov (2013), "My dream playground workshop: involving children in participatory design," in: ARCHHIST '13 Proceedings: Politics in the History of Architecture as Cause \& Consequence, Istanbul, DAKAM, pp. 106-115.

Frost, Joe L. (1985), "History of playground safety in America", Children's Environments Quarterly Vol. 2, No 4, pp. 13-24.

Frost, Joe L. (2006), "The dissolution of children's outdoor play: causes and consequences", presented at The Value of Play: A forum on risk, recreation and children's health. May 31, 2005. Available at: http://www.ipema.org/ news_articles/06/Common_Good.pdf. Accessed April 15, 2013.

Gantcheva, Roumiana - Alexander Kolev (2001), "Children in Bulgaria: Growing impoverishment and unequal opportunities," UNICEF-Innocenti Working Papers No 84, Florence, UNICEF

Gawler, Meg (2005), Useful Tools for Engaging Children in Participatory Evaluation [Pdf], UNICEF/CEE/CIS Regional Office. Available at: https:// issuu.com/learneasy/docs/tools-for-participatory-evaluation.

November 14, 2014.

Gharahbeiglu, Minoo (2007), "Children's interaction with urban play spaces in Tabriz, Iran", Visual Studies Vol. 22, No 1, pp. 48-52. http://dx.doi. org/10.1080/14725860601167192

Ginsburg, Kenneth R. (2007), "The importance of play in promoting healthy child development and maintaining strong parent-child bonds", Pediatrics Vol. 119, No 1, pp. 182-191. http://dx.doi.org/ 10.1542/peds.2006-2697

Groves, Leslie - Hugh McNish (2008), Baseline Study of Play at Merrylee Primary School, Glasgow, Forestry Commission of Scotland

Hasirci, Deniz (2008), "The peace mural: a PARTicipatory project between children from Chios, Greece and Izmir, Turkey", Children, Youth and Environments Vol. 18, No 2, pp. 236-249.

Herrington, Susan (2008), "Perspectives from the ground: early childhood educators' perceptions of outdoor play spaces at child care centres", Children, Youth and Environments Vol. 18, No 2, pp. 64-87.

Hirt, Sonia A. (2005), "Planning the post-communist city: experiences from Sofia", International Planning Studies Vol. 10, Nos 3-4, pp. 219-240. http:// dx.doi.org/10.1080/13563470500378572

Hofstede, Geert (1991), Culture and Organizations: Software of the Mind, London, McGraw Hill

Hofstede, Geert (2001), Culture's Consequences: Comparing Values, Behaviours, Institutions, and Organizations Across Nations, Thousand Oaks, Sage Publications 
Holleran, Max (2014), “Mafia Baroque': post-socialist architecture and urban planning in Bulgaria", The British Journal of Sociology Vol. 65, No 1, pp. 121-142. http://dx.doi.org/10.1111/1468-4446.12052

Jansson, Märit (2008), "Children's perspectives on public playgrounds in two Swedish communities", Children, Youth and Environments Vol. 18, No 2, pp. 88-109.

Jeorges, Bernward (1999), “Do politics have artefacts?”, Social Studies of Science Vol. 29, No 3, pp. 411-431. http://dx.doi.org/10.1177/030631299029003004

Keenan, Caroline (2007), "Meeting youth where they live: participatory approaches to research with marginalized youth engaged in urban agriculture", Children, Youth and Environments Vol. 17, No 3, pp. 198-212.

Korpela, Kalevi (2002), “Children's environment,” in: Bechtel, Robert B. Churchman, Arza, eds., Handbook of Environmental Psychology, New York, John Wiley \& Sons, pp. 363-373.

Meire, Johan (2007), "Qualitative research on children's play: a review of recent literature," in: Jambor, Tom - Gils, Jan van, eds., Several Perspectives on Children's Play: Scientific Reflections for Practitioners, Antwerp, Garant, pp. 29-68.

Parsons, Ashley (2011), Young Children and Nature: Outdoor Play and Development, Experiences Fostering Environmental Consciousness, and the Implications on Playground Design, Unpublished Master's thesis, Blacksburg, Virginia Polytechnic Institute and State University

Percy-Smith, Barry (2002), "Contested worlds: constraints and opportunities in city and suburban environments in an English Midlands city," in: Chawla, Louise, ed., Growing up in an Urbanizing World, London, Earthscan Publications, pp. 57-80.

Pursell, Carroll (2011), “The safe and rational children's playground: strategies and technologies since the nineteenth century", History Australia Vol. 8, No 3, pp. 47-74.

Raycheva, Lilia- Katya Hristova, Dessislava Radomirova, and Rossen Ginev (2004), "Bulgaria: childhood in transition," in: Jensen, Ann Magrit et al. eds., Children's Welfare in Ageing Europe, Vol. II, Tartu, University of Tartu Press, pp. 469-526.

Roe, Maggie - Kathryn Scott (2008), The Participation of Children in Landscape Decisions. Available at: www.ciudad-derehos.org, Accessed March 17, 2014. Sandseter, Ellen Beate Hansen - Leif Edward Ottesen Kennair (2011), "Children's risky play from an evolutionary perspective: the anti-phobic effects of thrilling experiences", Evolutionary Psychology Vol. 9, No 2, pp. 257-284. http://dx.doi.org/10.1177/147470491100900212 
Soler-Adillon, Joan - Jaume Ferrer - Narcis Pares, eds., (2009), A novel approach to interactive playgrounds: the interactive slide project," in: Proceedings from IDC 2009: The 8th International Conference on Interaction Design and Children, New York, ACM, 131-139.

Solomon, Susan G. (2014), The Science of Play: How to Build Playgrounds that Enhance Children's Development, London, University Press of New England State Newspaper (February 7, 2009), Ordinance on the terms and conditions for the device and the safety of playgrounds. Available at: http://dv.parliament.bg, Accessed January 23, 2013.

Valentine, Gill (2004), Public Space and the Culture of Childhood, Aldershot, Ashgate Publishing

Waller, Tim (2006), "Don't come too close to my octopus tree: recording and evaluating young children's perspectives of outdoor learning", Children, Youth and Environments Vol. 16, No 2, pp. 75-104.

Winner, Langdon (1980), "Do artifacts have politics?", Daedalus (Modern Technology: Problem or Opportunity?) Vol. 109, No 1, pp. 121-136. 


\section{TABLES}

Table 1. Mosaic Design

\begin{tabular}{ccccc}
\hline Activity & Theme & Data Type & Data Tool & Findings \\
\hline $\begin{array}{c}\text { Drawing pictures } \\
\text { and modeling clay }\end{array}$ & $\begin{array}{c}\text { Children's own } \\
\text { playground }\end{array}$ & $\begin{array}{c}\text { Videos, photos, } \\
\text { and interview } \\
\text { notes }\end{array}$ & $\begin{array}{c}\text { Standardized } \\
\text { documents }\end{array}$ & $\begin{array}{c}\text { Prioritization of the } \\
\text { FPDs (the grid with } \\
\text { total scores) }\end{array}$ \\
\hline Modeling clay & $\begin{array}{c}\text { Children's favorite } \\
\text { equipment in their } \\
\text { own playground }\end{array}$ & $\begin{array}{c}\text { List of verbal } \\
\text { declarations }\end{array}$ & Written notes & $\begin{array}{c}\text { Frequency of each } \\
\text { specific type of } \\
\text { equipment mentioned }\end{array}$ \\
\hline Interviews & $\begin{array}{c}\text { Children's dream } \\
\text { playground }\end{array}$ & Videos & $\begin{array}{c}\text { Observations on a } \\
\text { specific trend }\end{array}$ & $\begin{array}{c}\text { Quotations from } \\
\text { children supporting } \\
\text { the trend }\end{array}$ \\
\hline $\begin{array}{c}\text { Flower-planting } \\
\text { Children's own } \\
\text { playground }\end{array}$ & Videos and photos & $\begin{array}{c}\text { Observations on a } \\
\text { specific trend }\end{array}$ & $\begin{array}{c}\text { Quotations from } \\
\text { children supporting } \\
\text { the trend }\end{array}$ \\
\hline $\begin{array}{c}\text { Teachers' } \\
\text { Children's own } \\
\text { playground } \\
\text { prioritization of } \\
\text { FPDs }\end{array}$ & $\begin{array}{c}\text { Children's dream } \\
\text { playground }\end{array}$ & documents & Written \\
declarations & Teachers' & $\begin{array}{c}\text { Teachers' } \\
\text { perspectives on }\end{array}$ \\
\hline $\begin{array}{c}\text { Children's free } \\
\text { play }\end{array}$ & $\begin{array}{c}\text { Public playground } \\
\text { prioritization of the } \\
\text { FPDs }\end{array}$ \\
\hline
\end{tabular}

Note: FPD=Functional Playground Dimension.

Table 2. Prioritization of FPDs

\begin{tabular}{ccccc}
\hline & \multicolumn{2}{c}{$\begin{array}{c}\text { Group 1: Prioritization of FPDs for a } \\
\text { post-Cold War playground design }\end{array}$} & \multicolumn{2}{c}{$\begin{array}{c}\text { Group 2: Prioritization of FPDs for a } \\
\text { Cold War playground design }\end{array}$} \\
\hline Children's & 1. Joy & $(127)$ & 1. Joy & $(59)$ \\
perceptions & 2. Socialization & $(86)$ & 2. Design & $(47)$ \\
& 3. Design & $(85)$ & 3. Socialization & $(42)$ \\
& 4. Nature & $(50)$ & 4. Safety & $(27)$ \\
& 5. Safety & $(46)$ & 5. Nature & $(20)$ \\
\hline Parents' & 1. Safety & $(91)$ & 1. Safety & $(91)$ \\
perceptions & 2. Joy & $(64)$ & 2. Joy & $(71)$ \\
& 3. Nature & $(59)$ & 3. Design & $(49)$ \\
& 4. Socialization & $(47)$ & 4. Nature & $(46)$ \\
& 5. Design & $(39)$ & 5. Socialization & $(43)$ \\
\hline
\end{tabular}

Notes: The total score for each FPD is indicated in brackets. $F P D=$ Functional Playground Dimension . $N=80$ 